\title{
ETNO-MATEMÁTICA EN INDÍGENAS ULWAS, COMUNIDAD DE KARAWALA, REGIÓN AUTÓNOMA ATLÁNTICO SUR, NICARAGUA
}

\author{
Minerva Soza Valverde ${ }^{[1]}$ \\ Alba Luz Dávila Espinoza ${ }^{[2]}$
}

\section{Resumen}

Esta investigación analizó los conocimientos etno-matemáticos que poseen los pueblos indígenas ulwas, comunidad de Karawala, Región Autónoma Atlántico Sur (RAAS), a partir de la identificación de las manifestaciones socioculturales que representan saberes etno-matemáticos ancestrales. La investigación fue cualitativa con enfoque antropológico. Se realizaron guías de observación, entrevistas y grupos focales con líderes, autoridades de la comunidad, docentes y ancianos.

Entre los resultados se obtuvo que el Sistema Numérico del Conteo con los Dedos; este conteo, los ancestros ulwas lo hacían con los dedos de las manos y de los pies, en el Sistema de Medición se identifican como unidades de medidas la vara, la jícara, los nudos en bejuco. También el empleo de conocimientos geométricos en la construcción de viviendas tradicionales, nasas y elaboración del metate. Estos aportes contribuyen a la revitalización cultural de los pueblos indígenas ulwas y a la gestión curricular en el Subsistema Educativo Autonómico Regional (SEAR), los cuales deben ser adoptados en la transformación curricular de los programas de la Educación Intercultural Bilingüe.

Palabras Clave: Etno-matemática, prácticas ancestrales, sistemas numéricos, medición, geometría.

\section{Summary}

This research examined the ethno-mathematical knowledge that the Ulwas indigenous people possesses, who are located in Karawala community, South Atlantic Autonomous Region (RAAS), based on the identification of sociocultural manifestations that the ethno-mathematical ancestral knowledge represents. The research was qualitative with anthropological approach. Observation guides were made, interviews and focus groups with leaders, community authorities, teachers and elders.

\footnotetext{
${ }^{[1]}$ Máster en Docencia Universitaria y Docente de matemática del recinto en URACCAN-Recinto Bluefields. sozaminerva@yahoo.com

${ }^{[2]}$ Máster en Psicopedagogía con mención en Docencia Universitaria y Secretaria Académica de URACCAN-Recinto Bluefields. albaluzda@yahoo.com
} 
Among the results obtained, it reflects the Counting Numerical System with the Fingers. This counting was done by the Ulwas ancestors with their fingers and toes. In the Measurement System several elements were identified as measuring units, such as the stick, the gourd, and the knots on liana. They also employed the use of geometric knowledge in traditional housing construction, and development of fish trap and grinding stone. These inputs contribute to the cultural revitalization of the Ulwas indigenous people and to the curricular management in the Regional Autonomous Education Subsystem (SEAR), which should be adopted in the curricular transformation of the Bilingual Intercultural Education program.

Keywords: Ethnomathematics, ancestral practices, numerical systems, measurement, geometry.

\section{Introducción}

Este estudio aborda los conocimientos etno-matemáticos adquiridos por los pueblos indígenas ulwa de la comunidad de Karawala, sede municipal de la Desembocadura del Río Grande de Matagalpa, Región Autónoma Atlántico Sur.

Se identifica las matemáticas vernáculas de la cultura ulwa concebidas como etno-matemáticas y se describen las experiencias, sabiduría y cosmovisión del pueblo indígena ulwa sobre estas prácticas ancestrales, de manera general. Esta investigación es la primera que obedece a esta temática en estos pueblos; los resultados serán devueltos a los comunitarios como parte de su acervo cultural; asumiendo que la interactividad entre los pobladores ulwas con otras etnias, genera cambios en las prácticas de sus saberes.

Según D'Ambrosio (2005, p. 22), citado por Droguett (2008, p. 7), se puede encontrar matemáticas no sólo en el aula y en los textos, sino también en la vida cotidiana. "lo cotidiano está impregnado de saberes y haceres propios de la cultura" a partir de lo cual es preciso responder las interrogantes: ¿Cuáles son los conocimientos etno-matemáticos que los ancestros ulwas han heredado a las nuevas generaciones? ¿Cuáles son los modos de matematización del pueblo ulwa de Karawala en las principales actividades económicas, sociales y culturales? ¿En qué consisten los saberes etno-matemáticos sobre el Sistema Numérico, Sistema de Medición y la Geometría empleada por los ulwas en sus prácticas cotidianas?

Los resultados permitirán la preservación de la sabiduría ancestral del pueblo indígena ulwa y la inclusión de conocimientos, además de restaurar el respeto y la dignidad por sus tradiciones culturales, con prioridad en la inclusión de conocimientos de rescate de la identidad cultural y el fortalecimiento del SEAR. 


\section{Revisión de Literatura}

\section{Etno-matemática}

La etno-matemática analiza los aspectos antropológicos, históricos, geográficos y psicofilosóficos que inciden en el desarrollo del conocimiento matemático. Tal acercamiento permite ver a las matemáticas como una actividad humana dinámica y vibrante de los diversos grupos culturales y lograr establecer un contexto multicultural en la enseñanza y aprendizaje de las matemáticas y hacer conexiones entre cultura, matemática, historia, geografía, psicología, antropología y otras ciencias sociales (Ortiz, 2004).

La etno-matemática implica una conceptualización muy amplia de la matemática y del 'etno'. Una visión amplia de la matemática incluye contar, hacer aritmética, clasificar, ordenar, inferir y modelar. 'Etno' involucra "grupos culturales identificables, como sociedades nacionales - indígenas (tribus), grupos sindicales, niños de ciertos rangos en las edades, sectores profesionales, etc." e incluye su "su jerga, códigos, símbolos, mitos y hasta sus maneras especificas de razonar e inferir" (Boletín del ISGEm, No. 1985)

Según D’ Ambrosio citado por Blanco (2008), el objetivo de la etno-matemática es llevar esas prácticas a la escuela y a la investigación, porque es muy difícil hacer investigación cerrada en la disciplina, es muy importante que la investigación sea en matemática pura o aplicada, historia, filosofía, sea una investigación que se relacione con otras áreas del conocimiento, la matemática no está aislada de las otras maneras del conocimiento sea arte, religión, arquitectura; todo eso, entonces es integrar la matemática a otras formas del conocimiento, ese es un objetivo que se espera que la Etno-matemática contribuya, además de una enseñanza mejor.

El pueblo indígena ulwa se puede considerar una sociedad culturalmente identificable, de acuerdo a Rizo (2003). En la cultura material se contemplan algunos elementos que las componen, tales como las técnicas y los conocimientos: desde los instrumentos para pescar y trabajar la tierra, hasta los trastes de la cocina o las armas para cazar o defenderse (...); de la misma manera las técnicas para utilizar los instrumentos y preservarlos, así para como fabricarlos y adquirirlos. Las costumbres también forman parte de esta cultura material. Los valores definen las normas de comportamientos expresados en criterios que indican lo deseable o no deseable de acuerdo a los intereses de una cultura. 


\section{Materiales y Métodos}

En la comunidad de Karawala se percibe un ambiente intercultural y plurilingüe, puesto que la población está constituida por diversas etnias: mestizos, creoles, misquitus y ulwas. Los pobladores en su mayoría manejan más de una lengua, pero predomina el miskitu según la opinión de algunos pobladores de la comunidad. Por lo tanto se identificó esa población ulwa, los cuales proveyeron la información necesaria para lograr los propósitos planteados.

La metodología es cualitativa y con enfoque etnográfico en el quehacer cotidiano de los comunitarios en el ámbito económico, cultural y social; además porque analiza los hechos significativos de las prácticas de saberes etno-matemáticos como un fenómeno propio que se desarrolla en un ambiente natural y cultural, asociándose de este modo con lo fenomenológico, lo inductivo, lo holístico y lo subjetivo.

La metodología fue desarrollada a través de grupos focales y entrevistas. Los protagonistas que participaron como actores claves son líderes autoridades de la comunidad, docentes y ancianos pertenecientes al pueblo indígena ulwa.

Para el análisis se consideraron aspectos objetivos y subjetivos, cuantitativos y cualitativos; el estudio se personificó con la participación directa de la investigadora quien interactuó con los protagonistas involucrados.

\section{Resultados y discusión}

\section{Manifestaciones culturales de los ulwas en la representación etno-mátemática}

Se percibió que el pueblo ulwa cuenta con conocimientos etno-matemáticos que en la actualidad no todos son practicados en su vida cotidiana.

El conteo era considerado como un don que Dios les había dado, los conteos eran perfectos. El conteo lo hacían con el cuerpo: usaban los dedos, tardaban para contar, se veían obligados a responder de manera exacta, repetían el conteo varias veces. En el conteo hacían uso de las manos y de los pies, en este caso la medida se llamaba un cuerpo (muih as luih) y el conteo sólo con ambas manos, representaba medio cuerpo salap.

Según los informantes, al realizar conteos con los dedos estos pasaban de un dedo a otro, lo que demuestra que tenían bien claro el concepto de sucesor para la construcción de conjunto de números finitos; en la medida en que las cantidades iban creciendo, se hizo necesario un sistema de representación más práctico, expresan algunos informantes que los ancestros contaban con los dedos de las manos y de los 
pies, y al llegar a contar con los veinte dedos posiblemente hacían un corte para volver a empezar; a esto le llamaban un cuerpo, razón por la cual en este estudio se asocia este conteo con un sistema de numeración vigesimal o sea un sistema numérico de base veinte, y probablemente con una base auxiliar de cinco como el sistema numérico maya, puesto que relacionan el conteo con las extremidades del cuerpo en la que cada una contiene cinco unidades.

Se puede apreciar cómo de manera implícita manejaban en la construcción de objetos mentales la noción de conjunto, en el sentido de la agrupación de los dedos y de la misma manera el uso de los números enteros: específicamente de la unidad como un todo (un cuerpo); a la vez hacían uso de los números racionales mientras expresaban el medio cuerpo, que podía ser representado por las manos o por los pies.

Knight (2008), en la Historia oral de Karawala, refiere con respecto a la fecha de la fundación de Karawala que la definición del año es resultado de una investigación, auxiliándose de nudos hechos en cuerda o bejuco, pues en ese momento Luastin Simón a su llegada a Karawala llevaba consigo un bejuco de doce nudos, la suma de estos nudos representaba su edad. Podemos decir que desde entonces los indígenas estaban manejando el concepto de adición, de reparto y proporcionalidad.

En las entrevistas colectivas hechas a docentes, manifestaron que los ancestros tenían sus propias formas de conteo, para contar utilizaban distintos objetos (granos, semillas, huesos), hacían nudos en bejuco, marcaban en el suelo, usaban los pies y las manos. Consideran que actualmente en los hogares las familias no comparten los saberes ancestrales etno-matemáticos con la niñez en relación con la disciplina de matemáticas en la escuela primaria, depende en parte de algunos contenidos que para su desarrollo utilizan material concreto como piedras, palitos, palillos de fósforos, tapas de gaseosa; asimismo, estos materiales son utilizados para resolver operaciones de suma y resta. Los ancianos saben hacer conteos o cálculos mentales para resolver operaciones de suma, resta, multiplicación y división en situaciones cotidianas que se les presentan, a la vez se preocupan porque el uso de la tecnología moderna ejemplo: calculadoras, estas han influenciado en la falta de prácticas de los conocimientos ancestrales.

Se podría asumir que las manos y los pies fueron los instrumentos más utilizados para realizar el conteo en las actividades cotidianas de los ancestros ulwas; "el cálculo con las manos es un fenómeno antropológico de gran importancia como manifestación de la pluriculturalidad. Usar las manos para resolver problemas aritméticos es una técnica casi universal, pero la manera de hacerlo es muy diverso" Schroeder (compilado por Lizarzaburu 2001, p. 200).

Nuestros ancestros no tenían una educación completa, pero ellos se comunicaban mediante un cálculo, para tener una actividad colocaban estacas que les servían para 
definir el número de días de la actividad laboral, sacaban una estaca al terminar cada día. El trabajo finalizaba hasta levantar todas las estacas y posteriormente pasaban días de descanso o convivencia familiar. Luego, se trasladaban con las estacas a otro lugar.

La etno-matemática de este grupo sociocultural está en un nivel inicial de sistematización en la escuela; aún se emplean técnicas pedagógicas obsoletas, la preparación de los docentes es necesaria para brindar una educación de alto nivel técnico y pedagógico a la niñez cuya lengua y culturas son autóctonas. Knight (Indígena ulwa, 2010).

\section{Sistema de Medición}

Medidas de longitud, los informantes mencionan que los ancestros contaban con algunas unidades de medida entre ellas la vara, las manos, los pies. La vara era utilizada para efectuar diferentes medidas, ejemplo: la vara con una longitud igual a la medida tomada desde los pies hasta la punta de los dedos de las manos, con los brazos extendidos; generalmente era utilizada para medir las parcelas. La vara (panbaka) tenía como medida la longitud desde los pies hasta la punta de los dedos de la mano estirada de forma vertical, sólo los ancianos cortaban esa vara.

Igual a la longitud que forman los brazos abiertos o sea dispuestos en posición horizontal, esta longitud era representada a través de una vara y la medida era llamada salah bu. Esta medida también era utilizada en las construcciones. De igual manera la vara era usada para medir la estatura de la niñez al nacer y controlar su crecimiento. Actualmente la vara es usada por el síndico para distribuir el espacio o el territorio de manera equitativa que se le asigna a cada familia, previo a la limpieza comunal que temporalmente se realiza en el municipio.

Las manos cerradas y unidas por los dedos pulgares, eran utilizadas para medir la longitud de objetos pequeños y para medir longitudes mayores se cortaba una vara del tamaño que tenían los brazos abiertos de la persona (hombre). La medida de la vara era conservada para realizar otras mediciones durante la actividad laboral o en las medidas que hacían en la distribución de la tierra que los padres heredaban a sus hijos.

También, en la siembra de yuca y maíz la distancia que se conservaba entre cada semillero era de un paso, lo que equivalía a la longitud de un brazo; en la siembra de arroz y frijoles la separación entre cada semillero era de una longitud igual al antebrazo, esta medida era llamada ting as.

Para tomar la medida de las manos cuando estas eran grandes tenían que superponer los dedos pulgares, mientras que para manos pequeñas sólo se unían las abiertas; con los pies se hacían medidas lineales trasponiendo uno con otro hasta agotar el espacio que se quería medir. 
Cuando se trataba de medir grandes distancias, la unidad de medida que se tendría que utilizar la reproducían para efectuar la medición con mayor rapidez, dicha medida era equivalente a la estatura de una persona de la comunidad, de modo que todos los interesados de hacer estas medidas especialmente de las parcelas tendrían que acudir a la misma persona, quien determinaba dicha medida la cual era llamada muih as. Aunque en algunos casos los comunitarios preferían utilizar el bejuco añadido para evitar las pequeñas longitudes que quedaban sin medirse en el momento de trasponer la vara.

Otra medida de longitud es la que se tomaba de la estatura de una persona más cuatro dedos de la mano (la mano ubicada sobre la cabeza en posición horizontal), esta persona era previamente autorizada, servía para medir las parcelas para la siembra. Las personas de estatura baja recurrían a las personas altas para solicitar la medida completa.

Durante la siembra de yuca en el invierno, cada trozo medía la longitud del antebrazo de la persona que sembraba, del cual sólo se introducía en la tierra la mitad, mientras que en el verano el trozo medía la mitad de la medida del trozo sembrado en el invierno y era introducido en la tierra casi todo, es evidente que usaban conceptos matemáticos dentro del quehacer cotidiano.

Cortaban la fruta de henequén (awawah) la ponían en agua, luego la golpeaban con un palo y de ahí sacaban la cuerda para pescar, y como anzuelos usaban planta de pejibaye, dientes de guilla, guatusa y uñas de tigres. El arco y la flecha eran usados para cazar animales entre ellos muchos peces y animales como el danto, chancho de monte, pavón; la flecha para tirar al aire tenía una longitud igual a una de las extremidades superiores, pero para tirar en la tierra la medida era media brazada, el tamaño del arco era igual a una brazada (brazos extendidos de forma horizontal). Usaban otras medidas como el bejuco que servía para medir parcelas o predios grandes.

El cayuco (pipante) era el medio de transporte que utilizaban para movilizarse a pescar, trabajar o cazar; se construía de caoba y su tamaño dependía de la cantidad de las personas que lo iban a usar. Las medidas según recuerdan eran las siguientes: El cayuco más pequeño medía 15 manos de largo por 3 de ancho; el mediano medía 24 manos de largo y 4 manos de ancho y el más grande medía 28 manos de largo y 8 de ancho.

\section{Medidas de capacidad}

Para los intercambios de alimentos utilizaban unidades de medidas conformadas por cucharas de madera y recipientes como el jícaro, etc. Las manos juntas tomadas en forma de una vasija, también eran usadas para medir determinada cantidad de productos que pudieran ser contenidos por ambas. 
Los ancestros no tenían un método de cálculo, pero si podían repartir cosas por cantidad, al compartir con otros repartían de manera equitativa. En el intercambio de productos dependía de lo que se iba a compartir, daban y recibían en la misma cantidad cualquier otro producto, para esto disponían de una medida especial el jícaro (sutak). Comunitario ulwa 2010.

Medidas de tiempo, los indígenas ulwas se orientaban en el tiempo básicamente mediante la observación del movimiento del Sol, la Luna y las estrellas y consideraban que algunos fenómenos de la naturaleza intervenían en su vida, a la vez identificaron dos estaciones: seca y lluviosa. Comunitario ulwa 2010.

Los astros tenían influencia en las actividades cotidianas del pueblo ulwa; observaban la posición que toma el Sol durante el proceso de rotación de la Tierra, de esta manera pudieron determinar el inicio, medio y fin del día; a la vez les servía de orientación la sombra que proyectaban objetos y personas con los rayos del Sol. Los cambios de la Luna fueron determinantes para definir el calendario, además fue una guía fundamental para las actividades de caza, pesca y agricultura, en luna llena aprovechaban para cazar en la abundancia de animales como el jabalí, venado, guilla y pavón, mientras que en otros períodos eran escasos; asimismo, se creía que los labios de los peces eran más fuertes en la luna llena y, de la misma manera la plantación en luna llena aseguraba mejores cosechas.

Para cortar un árbol tomaban en cuenta los períodos de la Luna; cinco o seis días después de la luna nueva cortaban el árbol, ya que tenían la creencia de que al no cumplir con esta condición a los tres meses penetraba algún animal que lo destruía. El canto de las ranas y la abundancia de zancudos eran señales de lluvia en el verano.

El vuelo de la lora de ida y regreso, según la posición geográfica, era el mejor reloj para la hora de entrada y salida de la jornada laboral. En la entrevista colectiva los informantes manifiestan que el calendario que regía la vida de los ancestros estaba sujeto a muchos períodos de abundancia y reproducción de los animales.

Geometría, las figuras geométricas han sido relacionadas con las figuras o imágenes que se encuentran en la naturaleza: altura de un cerro, figura que tienen los animales, forma de los espacios (ríos y lagunas).

En el quehacer cotidiano de los ulwas hacían uso de la geometría en la construcción de sus canoas para la caza y pesca, las construcciones de sus viviendas respondían a una forma geométrica, la distribución de las parcelas para el cultivo y tierras para las 
familias, el orden en que se sembraban los plantíos también obedecían a una forma geométrica, los instrumentos usados para la alimentación tomaron formas diferentes según el interés para lo que eran creados, pero posiblemente el origen se encuentra en el jícaro que al parecer era una fruta de mucha abundancia. Del jícaro se hicieron cortes en posiciones diferentes los cuales produjeron utensilios para solventar las necesidades de la cocina; también, agregan los comunitarios, que del bambú hacían cucharas. Se podría afirmar que el mismo medio natural en que se desarrollaron los indígenas alimentó y enriqueció la sabiduría de los ancestros.

Usaban rectas paralelas para las sillas y bancos, redondo para los platos y mesas, curvas para los caminos y chozas, formas geométricas empleados por los ulwas fueron ovalado (entrevista con comunitario ulwa).

Los ancestros construían las viviendas (chozas) con columnas en forma de estacas, no usaban más que bejucos para sostener las varas entre sí, el bambú y la palma servía como techo para cubrir las chozas. La búsqueda de materiales dependía del tamaño de la construcción. En los tejidos de palmas confeccionados combinaban figuras geométricas.

\section{Los conocimientos matemáticos que emplean en su arquitectura o urbanismo (patrones o formas geométricas)}

Las principales actividades de los indígenas ulwas eran y siguen siendo la caza, la pesca y la agricultura; para el aseguramiento de la alimentación los indígenas se valían de herramientas que facilitaran la captura de animales, para lo cual usaban flechas, lanzas y cuerdas hechas del hilo de henequén con anzuelos hechos de dientes de animales; además, elaboraban nasas como la que se muestra en la figura, hechas de madera (varas) amarradas con bejucos, las cuales se introducían en el agua con carnada que motivara a los peces entrar a alimentarse en ella. Podemos observar su forma cilíndrica, una de las bases del cilindro es a la vez la base de un cono truncado que se encuentra en su interior y que tiene como fin permitir a los peces introducirse en la trampa, pero que al llegar al extremo de la parte truncada del cono quedan en la parte interna del cilindro donde la salida ya no es posible. Esta nasa tiene por un lado (segmentos que unen las bases) del cilindro, una puerta que se abre para sacar los pescados cuando esta es retirada del agua. 


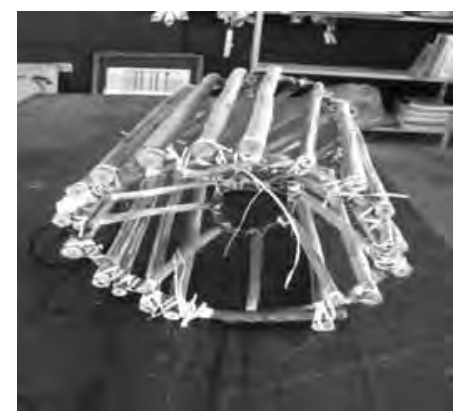

Figura No. 1. Nasa o Tramoa.

Entre los alimentos que cultivaban los ulwas está el arroz, por la necesidad de sacar del grano de arroz la granza se ingeniaron construir el pilón o mortero (unuk); con este instrumento los indígenas golpeaban el arroz con un pisón hasta dejarlo en condiciones de ser cocinado. El mortero actualmente es usado por los pobladores con el mismo fin y es hecho de madrera de níspero, almendro, etc., la parte superior del pilón tiene forma de cono circular recto, la base del pilón tiene forma circular.

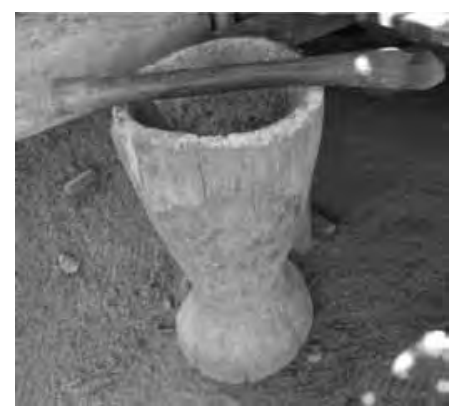

Figura No. 2. Pilón o Mortero.

En la construcción del mortero se han empleado muchos conocimientos de conceptos geométricos como: el cono como un sólido geométrico. En los hogares el pilón es utilizado por la familia, es relevante observar en la comunidad de Karawala la precisión y el acabado con que se trabaja.

El tamaño o altura del pilón depende de la estatura de quien lo va a utilizar, pues en esta actividad participan niños, jóvenes, mujeres y hombres. 


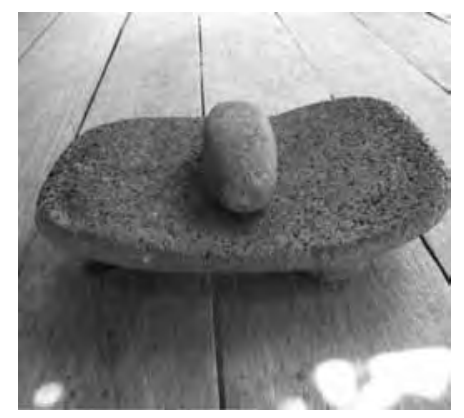

Figura No. 3. Metate.

El metate o piedra de moler (Ki tiknaka), es un artefacto elaborado por los ancestros indígenas para ser usado como molino de granos que sirven como bebida o alimentos básicos en los hogares de los ulwas, actualmente esta piedra es conservada en algunos hogares, hay variedad en el acabado y tamaño, ya que depende del grano que se vaya a moler. El metate por lo general tiene una forma ovalada o rectangular cóncava denominada plato, por tres elementos de apoyo vertical o inclinados de forma cilíndrica llamados soportes y contiene una pieza complementaria llamada mano que es la que comprime los granos sobre la piedra. Independiente del tipo de metate, los componentes que lo integran conforman un sistema estructural que por su grado de simetría, así como por su composición y equilibrio de fuerzas, hace del sistema un conjunto de puntos desde el punto de vista estático.

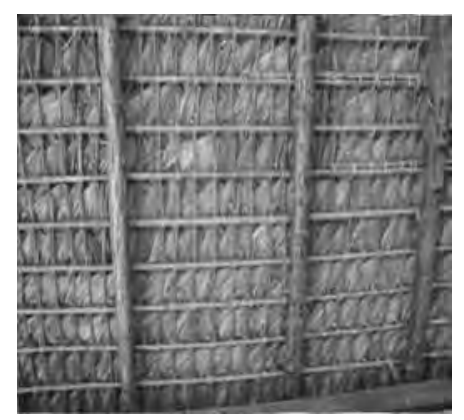

Figura No. 4. Techo de palma.

Techo de viviendas (tejido de hojas), los ancestros de los indígenas ulwas edificaban sus viviendas (chozas) con estacas amarradas con bejucos, el techo era construido con varas, palmas y también amarradas con bejucos, hoy en día todavía podemos observar que se conservan diseños como el de la fotografía y otros, este estilo del tejido de la palma demuestra el dominio de la técnica utilizada. El tejido lo hacen con la hoja de la planta llamada papta, los tallos de las hojas son amarrados en las varas que están en posición horizontal formando pequeños rectángulos, además que hacen uso de conceptos de paralelismo, de simetría y a la vez es de suponer que la visual con que trabajan les permite encontrar cierta simetría con respecto a las horizontales o verticales. 


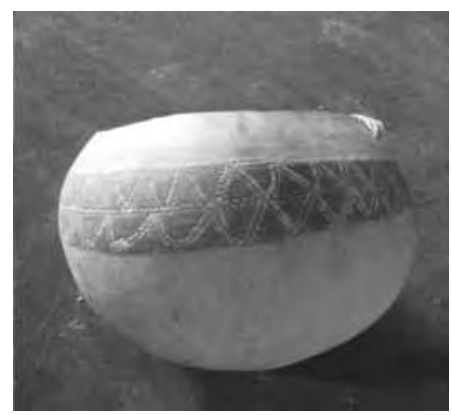

Figura No. 5. Jícara.

La jícara, es usada por los ulwas para recoger o guardar huevos de gallina, también hombres y mujeres la cargan con arroz cuando van al campo a sembrar; esta se cuelga a la cintura y van depositando los granos de arroz; las jícaras más pequeñas son usadas para tomar la chicha fuerte.

Esta jícara ha pasado por un proceso de raspado y pulido, tiene una franja de la corteza original que contiene una obra decorativa en la cual podemos apreciar figuras con forma de rombo, triángulo, líneas onduladas o quebradas. Las franjas están divididas en dos partes con una línea horizontal, sobre la línea horizontal se pueden identificar trapecios divididos en tres triángulos, a la vez se observan triángulos que contiene a la vez cuatro triángulos. Las líneas son formadas a partir de sucesiones de puntos, y la franja bordea el contorno de la jícara.

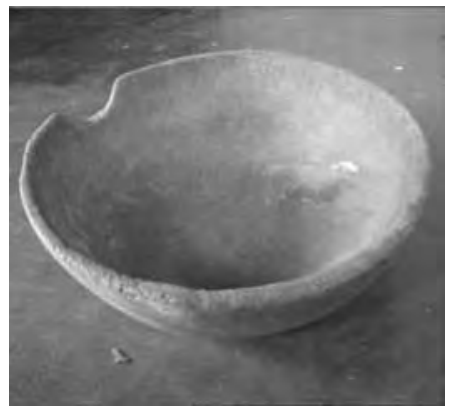

Figura No. 6. Baúl.

El baúl, este objeto hecho de caoba es usado por los indígenas para tomar los alimentos y fue usado como plato, para lavar trastos, ropas, para guardar el agua; el tamaño dependía de la actividad que se iba a realizar con él. Este artefacto posee una base circular, para darle la forma usaban el bejuco, a la vez implícitamente usaban los conceptos de radio o diámetro. 


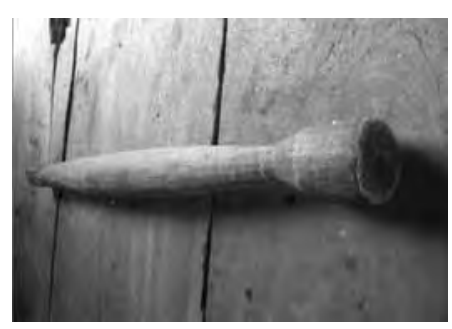

Figura No. 7. Molinillo.

El molinillo, este artefacto ha sido diseñado por los ulwas y elaborado en madera de caoba, a la vez en los hogares es utilizado en la cocina para hacer batidos de diferentes frutas o bastimento. En este artefacto se observa el pulido y el acabado muy atractivo.

Platos, entre los utensilios de alimentación los ulwas elaboraban platos en madera con una forma circular y en los cuales grababan algunas figuras que dieran mayor relevancia al objeto.

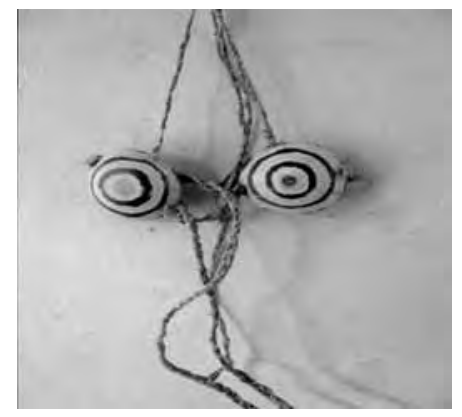

Figura No. 8. El sostén.

El sostén, la ilustración muestra un componente de la vestimenta de las ulwas en tiempo de los ancestros, las mujeres lo utilizaban para cubrirse los senos, estos eran elaborados con jícaros. Podemos observar en la figura que estos portabustos se sujetaban en ese momento con bejucos. La figura muestra trazos que representan círculos concéntricos y podría decirse que su forma representa una elipse, una figura cónica. Estos artículos llevaban un proceso de elaboración para alcanzar la estética deseada, manifiestan que después de limpiarlos, le echaban al algodón un líquido sacado de una fruta lo que permitía que se pusiera blanco. Este artículo les mantenía los pechos muy bien y no les causaba ningún daño.

El Sistema Educativo Autonómico Regional (SEAR) como un modelo de educación alternativo basado en los principios de autonomía, interculturalidad, solidaridad, equidad de género, calidad y pertinencia ha reconocido la diversidad cultural, étnica y social como una realidad histórica del país, esta realidad no se puede obviar porque representa parte del patrimonio cultural, tiene como componentes fundamentales 
la formación de recursos humanos idóneos en el campo de la Educación Intercultural Bilingüe, la transformación curricular en todas sus etapas y niveles, así como la elaboración de textos y materiales didácticos. El compromiso de este sistema redunda en una educación endógena, holística, pues debe considerar la formación de las personas dentro de un complejo sistema de relaciones que involucra a todos los seres del universo, a la naturaleza y a la vida.

La relación que hay entre los saberes matemáticos cotidianos de los pueblos ulwas y los saberes matemáticos escolares durante el proceso de enseñanza aprendizaje. Desde el punto de vista fenomenológico los procesos de enseñanza aprendizaje se orientan a partir de los fenómenos como fuente de aprendizaje, la didáctica como organización de dichos fenómenos y el aprendizaje como construcción de objetos mentales los cuales son tomados del pensamiento común o construidos como objetos matemáticos informales, representan nociones suficientemente elaboradas; los objetos mentales no son conceptos construidos técnicamente como en matemáticas, los objetos mentales permiten organizar los fenómenos. El aprendizaje de las matemáticas debe comenzar a partir de los objetos mentales construidos a través de la experiencia, conocimientos y el quehacer cotidiano de la niñez y no a partir inmediatamente de los conceptos matemáticos formales.

\section{Conclusiones}

El estudio de la etno-matemáticas de los pueblos indígenas en América Latina ha ido tomando mucha relevancia en cuanto a que existen muchas investigaciones que describen la matemática que los ancestros han heredado a las nuevas generaciones, específicamente se refiere a aquellos saberes adquiridos de un modo natural los cuales están fundamentados en la experiencia cotidiana de los indígenas y que a su vez revelan el modo de pensar, de sentir y de ver el mundo. Diferentes estudios realizados están dirigidos a conservar y revitalizar diferentes culturas.

A través de este estudio se ha podido comprobar que los ancestros de los ulwas en sus convivencias, migraciones, desplazamientos y encuentros entre diferentes pueblos y culturas aún conservan muchos conocimientos, saberes y tradiciones, aunque se han producido cambios desde sus propias dinámicas internas y por todas aquellas influencias e incidencias externas impuestas por la modernidad y los sistemas económicos, lo cual representa una gran amenaza a la diversidad lingüística y cultural a pesar de que esta ha sido reconocida en el sistema jurídico y político de Nicaragua y en el Sistema Educativo. Ante tal amenaza, se requiere de procesos de revitalización que permitan a la cultura ulwa preservarse, florecer y desarrollarse creativamente, sin que los pueblos indígenas pierdan su identidad cultural.

La lengua ulwa como patrimonio cultural de este pueblo, constituye un conjunto de convenciones que les permite comunicarse e interrelacionarse, ha sido garante de 
la transmisión de conocimientos a las nuevas generaciones. Se considera dentro de la etno-matemática que las diferentes culturas poseen ideas diferentes y se fundamentan en la relación que hay entre la matemática y la cultura donde prevalecen los conocimientos y relacionados con los conocimientos de carácter global, la etno-matemática representa un proceso de enculturación con una perspectiva reivindicadora que pretende hacer referencias a las formas de estar y hacer las cosas en el mundo.

Algunos estudios que se han hecho sobre la lengua ulwa han demostrado que la población en los hogares practica mayormente la lengua miskitu, lo que ha implicado que hayan ido adoptando elementos de dicha cultura; de tal manera que algunos saberes ancestrales ya no formen parte de la actividad cotidiana de los mismos. En la experiencia de este estudio se verificó con los docentes de primaria el uso de la lengua ulwa en los procesos de enseñanza y en la escuela secundaria se desarrollan las clases en miskitu, ulwa, kriol y hasta en español de ser necesario. Se trabaja muy poco en el rescate de la cultura ulwa.

Durante la recolección de la información la comunicación con los ancianos se hizo en la lengua ulwa, aunque para algunos era más cómodo responder en miskitu y los demás encuestados en su mayoría respondieron en lengua miskitu. Sin embargo, hay muchas personas a nivel de la comunidad que tienen como propósito revitalizar la cultura ulwa. También se pudo percibir el entusiasmo que demostraron los indígenas en aportar a esta investigación.

Los ancestros de los indígenas ulwas tenían su propio Sistema de Numeración basado en el conteo con los dedos; según refieren los informantes, de manera generalizada coinciden en que el conteo que se realizaba se hacía con los dedos, pero de manera distinta a las formas de conteo que hacen otras culturas; es decir, lo extraordinario es que usaban los dedos de las manos y de los pies para realizar estos conteos; a la vez especifican que solamente era usado para llevar cálculos pequeños; pues, para contar grandes cantidades usaban estacas, palos, piedras, granos, etc. Es relevante en este método, que el conteo hasta veinte tenía una equivalencia a un cuerpo (Miuh as liuh) lo que implicaba haber contado con los dedos de las manos y los pies; y al hecho sólo con las manos representaba medio cuerpo (Salap).

Inclusive usaban los dedos o las falanges de los dedos para contar cantidades más pequeñas. Esta teoría se puede relacionar con el sistema numérico vigesimal de los mayas, cuya base es el veinte; probablemente este sistema numérico ulwa también tenga una base auxiliar de cinco en el sentido de que cada extremidad del cuerpo contiene cinco elementos. En cierto modo la construcción del sistema de numeración conserva el mismo concepto de sucesor y de agrupación para contar utilizado por las matemáticas de los mayas. 
Paralelo al conteo con los dedos también practicaban el conteo de los nudos en bejuco; que de acuerdo a los informantes estos servían para llevar controles exclusivos sobre el tiempo (años, días, horas), la edad, los embarazos, otros. Es interesante descubrir porqué este método de conteo de los nudos practicado por los indígenas incas quienes llegaron a América por el Sur, según la historia, también fue usado por los ulwas quienes de acuerdo a las teorías sobre los procesos de emigración procedentes del norte.

Para encontrar respuestas teóricas y prácticas a la revitalización cultural de los indígenas ulwas con respecto a los saberes etno-matemáticos que los ancestros han heredado a las nuevas generaciones, se hace necesario re-conceptualizar las matemáticas escolares, estudiar las prácticas pedagógicas que se aplican en el Programa Educativo Intercultural Bilingüe para que los estudiantes aprendan matemática en la lengua materna que le permitan una participación activa y contribuir al desarrollo cognitivo, fortalecer la autoestima partiendo de los saberes matemáticos de los ulwas. Cada sociedad tiene una definición de la matemática que utiliza y produce, no es sólo la generación y el individuo, sino que también la colectividad, la función que la matemática desarrolle en esta sociedad es lo que determina su definición. La matemática es mucho más que contar y medir, también se deben aceptar otras formas no académicas del hacer y el pensar de una sociedad.

En el quehacer cotidiano de los ulwas se identifican ciertos instrumentos y artefactos que los ancestros usaron como medidas de longitud, capacidad o de tiempo, manifestaciones culturales que hoy en día, algunas todavía forman parte de la herencia cultural que define su identidad étnica. Como unidad de longitud se conoce la vara, la cual es tomada en diferentes tamaños que se deben a la estatura de una persona más cuatro dedos y a una brazada; las manos, con la palma cerrada o abierta y los dedos pulgares unidos por la uña y las falanges de los dedos que servían para pequeñas mediciones; la longitud del brazo y del antebrazo también han sido utilizada para medir algunas longitudes; los pies, dispuestos de forma sucesiva han servido para medir largas distancias. Y el bejuco que ha sido una de las unidades de medida más práctica o con mayor precisión.

Como unidades para la medida de capacidad fue usada la jícara, elaborada en diferentes tamaños tenía propósitos distintos como: recipientes para tomar agua, refrescos, para alimentos cocidos o crudos, para la recolección de los pescados, de los huevos, en la agricultura para cargar los granos, otros; las manos, tomadas juntas en forma de recipiente servían para intercambiar alimentos especialmente; el pichel, la taza, la cuchara de madera, las ollas de barro, los platos de madera son otros objetos utilizados en la convivencia familiar para compartir alimentos de manera proporcional; o durante la preparación de los alimentos consumidos dentro de los hogares. El baúl, por sus múltiples usos se elaboraba en distintos tamaños, era útil como vasija para comer, para guardar granos, para lavar trastos, para lavar ropa, para depositar 
agua, etc. El pilón, es usado para desprender la granza del grano de arroz con el fin de prepararse para ser consumido, es confeccionado en diferentes tamaños según quien lo va a utilizar (hombres, mujeres o niños) y en gran medida depende de la cantidad de granos que se requiere procesar, si es para el núcleo familiar o para ser comercializado.

Contaban con medidas de tiempo como: los nudos en bejuco, con esta medida controlaban los años, días, la edad, los embarazos, etc. La abundancia y reproducción de algunos animales los inspiró a crear el calendario que contenía veinticuatro períodos, esto fueron reducidos a doce a partir de algunas investigaciones hechas en el territorio ulwa, refieren los informantes. El vuelo de la lora, históricamente ha servido como indicador de inicio o fin de la jornada del trabajo diario. El Sol, que a través de la sombra que proyectaban las personas les indicaba el receso intermedio de la jornada de trabajo. La Luna, mediante sus cambios o movimientos orientaba a los indígenas en el tiempo prudente para desarrollar las actividades de caza, pesca y agricultura.

En la confección de instrumentos, artefactos y edificaciones es relevante destacar que los ancestros de los indígenas ulwas desarrollaron una serie de conocimientos sobre geometría; refieren los informantes que la geometría practicada por los ancestros es una reproducción del medio natural con el que han socializado e interactuado los indígenas en su vida nómada. Algunas imágenes o diseños simplemente responden a las que proyecta el cielo y la tierra en su infinita dimensión. Los elementos fundamentales de la geometría tales como: las rectas y su clasificación tienen relación con la posición del tallo y ramas de los árboles, con la superficie, con los ríos; Las formas geométricas tienen su cimiento en la forma que tienen los astros (el Sol, la Luna, las estrellas, etc.) los lagos, las lagunas. Las chozas construidas tienen relación con las imágenes que proyectan los cerros, picos, volcanes y además utilizan técnicas interesantes para construir el techo, poniendo en práctica conceptos de rectas, ángulos, simetría, semejanza, figuras geométricas y cuerpos sólidos.

Los resultados de esta investigación representan parte del acervo cultural de los saberes etno-matemáticos de los indígenas ulwas. Por consiguiente, un estudio etno-matemáticos como una manifestación cultural de un pueblo indígena requiere de mucho tiempo y dinero invertido y de actores multidisciplinarios, para lograr consolidar todo el cúmulo de saberes y conocimientos que estos pueblos indígenas poseen. 


\section{Lista de referencias}

Blanco, H (2008). Entrevista al profesor Ubiratan D'Ambrosio. Revista Latinoamericana de Etnomatemática.

Blanco, H; Parra, A. (2009). Entrevista al profesor Alan Bishop. Revista Latinoamericana de Etnomatemática, 2(1). 69-74 http://www.etnomatematica.org/v2-n1-febrero2009/blanco-parra.pdf Consultado 10 de abril del 2010.

Blanco, H; Parra, A. (2009). Entrevista al profesor Alan Bishop. Revista Latinoamericana de Etnomatemática, 2(1).69-74 consultado el o2 de septiembre 2010. Consultado El 12 de Mayo del 2010.

Boletin del ISGEm Grupo Internacional de estudio de Etnomatemática. Volumen 1 Número 1 agosto 1985 .

Knight, L. y James, M. (2008). WALANGWAS. Historia Oral de la Comunidad De Karawala. Bluefields.

Lizarzaburu, A. E. y Zapata, G. (2001) Pluriculturalidad y aprendizaje de la matemática en América Latina. España: Ediciones Morata. Nicaragua.

Rizo, M. (2003). Materiales de apoyo para la formación docente en educación Intercultural. Managua: Terra Nuova. IPILC - URACCAN. 